\title{
Entre a segurança e a soberania alimentar: por uma abordagem crítica da produção e distribuição de alimentos
}

Valmir José de Oliveira Valério ${ }^{1}$

ReSumo: Devido ao fato de compor um debate ainda recente, sobretudo no âmbito acadêmico, o estudo da produção e abastecimento alimentar através dos conceitos de segurança alimentar e soberania alimentar tem provocado equívocos e imprecisões. Utilizados de maneira conjunta e "pacificada", os conceitos deixam escapar as contradições resultantes do confronto teórico e político inerente a cada definição. Referenciados em uma perspectiva espacial, enquanto a segurança alimentar está lastreada na generalização do movimento dos alimentos no espaço, de acordo com os interesses do capital comercial e industrial, a soberania alimentar tem como fundamento a produção local para abastecimento local/regional, cujo protagonismo e controle são exercidos pelo campesinato e não pelos atravessadores. De tal modo, tendo em vista os sentidos espaciais específicos que resultam de cada forma de organização da agricultura e da comercialização de alimentos, neste artigo analiso as implicações teóricas e práticas no âmbito da relação entre os conceitos de segurança e soberania alimentar.

Palavras-CHave: Soberania alimentar; Segurança alimentar; Dependência; Produção de alimentos; Abastecimento alimentar.

ABSTRACT: For being a recent debate, especially in the academic sphere, the study of food production and supply through the concepts of food security and food sovereignty has led to misconceptions and inaccuracies. Used in a joint and "pacified" way, the concepts let escape the contradictions resulting from the theoretical and political confrontation inherent in each definition. Referenced from the spatial perspective, while food security is based on the generalization of the food movement in space, according to the interests of commercial and industrial capital, food sovereignty is based on local production for local / regional supply, whose control are exercised by the peasantry and not by the middlemen. Thus, in view the specific spatial meanings resulting from each form of organization of agriculture and food marketing, this article analyzes the theoretical and practical implications of the relationship between the concepts of food security and food sovereignty.

KEYwORDS: Food sovereignty; Food safety; Dependency; Food production; Food supply.

\footnotetext{
${ }^{1}$ Mestre e doutorando em Geografia pela Universidade Estadual Paulista (UNESP) - campus de Presidente Prudente/SP Pesquisador do Núcleo de Estudos, Pesquisas e Projetos de Reforma Agrária - NERA / FCT / UNESP

Bolsista de doutorado da Fundação de Amparo à Pesquisa do Estado de São Paulo (FAPESP) E-mail: valjvalerio@yahoo. com.br
} 


\section{INTRODUÇÃO}

Na ciência, não há espaço para ingenuidades que associem a pesquisa científica a qualquer tipo de posicionamento dúbio ou, pior ainda, de pretensa neutralidade. De tal modo, o praticante de ciência não pode, jamais, adotar uma postura supostamente neutra ou que dê margem para interpretações nesse sentido, a não ser que queira advogar por "uma concepção mítica do que seja a ciência" (JAPIASSU, 1975, p. 11). Essa postura de neutralidade se manifesta em graus variados e de diferentes maneiras. De forma deliberada ou por imprecisão teórica e conceitual, algumas abordagens relacionam conceitos que, à luz da sua definição, mostram sentidos diametralmente opostos. Este tipo de abordagem "pacificada" tem por efeito ocultar (ou enfraquecer) concepções contrárias ao modelo hegemônico, de maneira a impor uma perspectiva conservadora em relação a propostas de desenvolvimento que não estejam alinhadas ao projeto dominante. No caso específico deste artigo, meu objetivo é colocar luz sobre as implicações teóricas e práticas da associação "despreocupada" da segurança à soberania alimentar, numa postura que desconsidera as particularidades de cada concepção em termos de projetos de sociedade ou, mais especificamente, de diferentes propostas de produção e abastecimento alimentar.

Mais que implicações meramente teóricas e conceituais, a operacionalização dos diferentes conceitos por meio de políticas públicas e/ou movimentos sociais resulta em propostas de desenvolvimento intrinsecamente conflitantes. Assim, com as atenções voltadas aos significados da produção e abastecimento sob diferentes perspectivas e modelos de sociedade, sobretudo no que se refere à dimensão do movimento dos alimentos no espaço, avalio os sentidos teóricos e práticos que demarcam uma abordagem crítica da produção e do abastecimento alimentar. Quando me refiro ao movimento dos alimentos no espaço, não quero com isso reduzir o espaço à dimensão das distâncias, mas sim destacar a importância da identificação dos circuitos espaciais e das distâncias percorridas pelos alimentos que abastecem determinado recorte territorial (VALÉRIO, 2015).

Por conseguinte, de início demarco a minha compreensão acerca dos contornos básicos (teóricos, políticos e práticos) que definem e, ao mesmo tempo, particularizam os conceitos de segurança alimentar e soberania alimentar. Em seguida, para além do embate teórico e conceitual, destaco os diferentes projetos de sociedade em disputa. Para tanto, a partir da abordagem oficial (Lei n ${ }^{\circ} 11.346$, de 15 de setembro de 2006) em torno da relação entre segurança e soberania alimentar, analiso o uso dos conceitos sob diferentes perspectivas teóricas e políticas, assim como as implicações práticas que resultam da sua operacionalização por meio de políticas públicas e/ou movimentos sociais. 


\section{SEGURANÇA ALIMENTAR: A INSTITUCIONALIZAÇÃO DA DEPENDÊNCIA}

O conceito de segurança alimentar surge, de acordo com Custódio et al. (2011, p. 02), no contexto europeu do início do século XX, definido naquele momento como "a capacidade de cada país de produzir sua própria alimentação, evitando assim vulnerabilidades". Da mesma forma, Menezes (1998) afirma que o termo segurança alimentar nasce logo após o término da $1^{\mathrm{a}}$ Guerra Mundial, no contexto da percepção de que "um país poderia dominar outro, se tivesse o controle sobre seu fornecimento de alimentos". De tal modo, o controle sobre o abastecimento alimentar representava uma importante arma, sobretudo quando utilizada por uma grande potência em relação a um país menos preparado e incapaz de produzir os alimentos necessários para atender a demanda da sua própria população. Portanto, a expressão "segurança alimentar" representa, na sua origem, um termo geopolítico fundado na concepção de estratégias militares (MENEZES, 1998, não paginado). (Grifo nosso)

A criação da Organização das Nações Unidas (ONU) em 1945 fortalece a difusão do conceito de segurança alimentar. Entretanto, isso acirra as divergências quanto aos seus conteúdos e significados. Internamente às recém-criadas organizações intergovernamentais, tais como a FAO (Organização das Nações Unidas para a Agricultura e Alimentação) e outras, existia uma forte tensão política entre os organismos que compreendiam o acesso aos alimentos em quantidade e qualidade como um direito humano inalienável dos povos e os que entendiam que a segurança alimentar poderia ser assegurada pela atuação dos mecanismos de mercado, entendimento este compartilhado pelo Fundo Monetário Internacional (FMI), Banco Mundial (BM), entre outros (MACEDO et al., 2009).

Até meados da década de 1970 os debates sobre o tema do abastecimento alimentar estiveram vinculados estritamente ao questionamento quanto à capacidade de produção de cada país. Por ocasião da $1^{\text {a }}$ Conferência Mundial de Segurança Alimentar, realizada pela FAO no ano de 1974, em um momento de baixa dos estoques mundiais de alimentos, derivada da quebra de safras em importantes países produtores, a ideia de segurança alimentar se afirmava como algo estritamente ligado à produção agrícola, fato que, concomitantemente, fortalecia o discurso da revolução verde. Com isso, o discurso hegemônico afirmava que o flagelo da fome e da desnutrição desapareceria com o aumento da produção agrícola, assegurado pela utilização maciça de insumos químicos, sobretudo fertilizantes e agrotóxicos. Embora a produção agrícola tenha aumentado quantitativamente, a fome e a desnutrição permaneceram, atingindo gravemente uma grande parcela da população mundial (MENEZES, 1998, não paginado). 
No Brasil, os debates em torno da segurança alimentar têm seus passos iniciais ainda em 1938, quando Josué de Castro elabora os primeiros Inquéritos Alimentares, análises pioneiras e clássicas sobre o fenômeno da fome no Brasil. Conforme nos indicam Macedo et al. (2009), estes trabalhos constituem o mais importante marco histórico do estudo da fome no país, com o qual Josué de Castro define a fome como um problema político. Desde então, ocorreram diversas iniciativas governamentais relacionadas à questão da fome, porém, nenhuma com êxito e continuidade. Segundo Maluf et al. (1996) é apenas no ano de 1986 que o tema da segurança alimentar surge no Brasil como elemento definidor de uma proposta política de abastecimento alimentar. À época, a segurança alimentar constituía apenas uma noção que buscava "avaliar o controle do estado nutricional dos indivíduos, sobretudo a desnutrição infantil, sob a égide da Vigilância Alimentar e Nutricional”.

Enquanto objetivo estratégico de governo, a segurança alimentar referenciaria a elaboração das políticas agrária, agrícola e agroindustrial, além da comercialização, distribuição e consumo dos alimentos numa perspectiva de descentralização e diferenciação regional. A descentralização seria, assim, fundamental para o estabelecimento da segurança alimentar, pois favoreceria a participação e o controle social das ações do governo. Ainda no contexto da segurança alimentar, é significativo o fato da Associação Brasileira de Agribusiness (ABAG) ter celebrado a sua fundação com a publicação de um livro no qual é proposto um tipo de "abordagem de agribusiness da segurança alimentar, avaliada como 'a principal responsabilidade social' dos agentes envolvidos no chamado 'agronegócios', que, por sua vez, seriam seus principais promotores". A despeito das aparentes "boas intenções" do setor, fica claro o viés de valorização das próprias atividades, no qual a segurança alimentar é concebida como instrumento dinamizador do processo de desenvolvimento do próprio agronegócio, capaz de assegurar "uma demanda sustentada que lhe permite retomar o crescimento" (MALUF et al., 1996).

As ações voltadas ao enfrentamento da questão da fome no Brasil registraram um importante passo com a criação do movimento Ação da Cidadania Contra a Fome, a Miséria e Pela Vida, movimento de escala nacional surgido no ano de 1993. Este movimento teve o mérito de colocar em relevo o drama vivido por aproximadamente 32 milhões de brasileiros nos campos e nas cidades, "além de colaborar fundamentalmente para a implantação do Conselho Nacional de Segurança Alimentar (CONSEA)". Criado em abril de 1993 como órgão de aconselhamento da Presidência da República, o CONSEA era composto por ministros e representantes da sociedade civil. No contexto da atuação do movimento Ação da Cidadania com o apoio do CONSEA, foi realizada em julho de 1994 a primeira Conferência Nacional 
de Segurança Alimentar (CNSA). Apesar das contribuições, esta primeira fase do CONSEA teve uma curta duração, sendo substituído ainda no final de 1994 pelo Programa Comunidade Solidária, que restringia a segurança alimentar à dimensão puramente assistencial (MALUF et al., 1996).

A primeira fase do CONSEA durou entre 1993 e 1994, sendo retomado apenas no ano de 2003. Na abordagem oficial (CONSEA, 2009), a proposta de construção de um sistema e de uma política nacional de segurança alimentar tem origem na efetivação de dois eventos realizados na década de 1980, um de caráter mais técnico e outro político. O primeiro, a elaboração do documento Segurança Alimentar: proposta de uma política de combate à fome, no âmbito do Ministério da Agricultura, ocorrido no ano de 1985. O segundo, a realização da Primeira Conferência Nacional de Alimentação e Nutrição (CNAN), no ano de 1986. As proposições no âmbito do CNAN "levaram, entre outras, à introdução do qualificativo nutricional à noção de segurança alimentar", o que viria a compor, posteriormente, a Lei de segurança alimentar e nutricional (LOSAN) (CONSEA, 2009).

Sancionada em setembro de 2006, a Lei de segurança alimentar e nutricional (BRASIL, 2006) consagra pela primeira vez o conceito de soberania alimentar. A Lei coloca a soberania alimentar como um dos princípios que a orientam, junto com o direito humano à alimentação. Apesar de representar um avanço, a soberania alimentar concebida no plano oficial vincula o "princípio da soberania alimentar" à segurança alimentar. Ou seja, de acordo com a Lei $n^{\circ} 11.346$, de 15 de setembro de 2006, a soberania alimentar está contida e subordinada à segurança alimentar, numa concepção que se limita à soberania enquanto capacidade de produção dentro do território nacional, o que representa apenas uma das escalas da soberania alimentar concebida originalmente no bojo da Via Campesina.

Ao se limitar à escala do território nacional, a concepção legal sobre soberania alimentar fecha os olhos para a existência de outras escalas, nas quais os alimentos ficam sujeitos à lógica predominante no atual sistema de produção e abastecimento alimentar, de modo que os alimentos peregrinam por todo o território numa lógica de valorização que desconsidera a qualidade da comida, além de minar a reprodução camponesa pela drenagem da renda, aprofundar o consumo de combustíveis fósseis e encarecer o produto final para o consumidor. Subentendidas à escala do território nacional, o abastecimento alimentar contempla uma rede de escalas que envolvem uma diversidade de sujeitos e territórios. É aí que o conceito de soberania alimentar utilizado no plano oficial encontra seus limites, pois por mais que a demanda nacional seja satisfeita em sua maior parte pelo abastecimento interno, o controle dos circuitos alimentares nacionais figura 
como trunfo do capital comercial no processo de valorização e não como expressão da capacidade de articulação dos sujeitos em um determinado território.

$\mathrm{O}$ conceito de segurança alimentar formulado pela FAO (CONSEA/FAO/ IICA, 2009) nos anos noventa definiu a alimentação como um direito humano de todas as pessoas, a ser garantido pelos governos. Apesar de consolidar um passo importante, estabelecendo que os governos resolvam os problemas relacionados à fome, a persistência do flagelo tem demonstrado que isso não é suficiente. Os debates oficiais em torno da segurança alimentar defendem o direito das pessoas a terem acesso a alimentos saudáveis e nutritivos, em consonância com o direito a uma alimentação adequada e ao direito fundamental de estarem livres da fome. Entretanto, alinhada com o neoliberalismo e a Organização Mundial do Comércio (OMC), a definição de segurança alimentar busca garantir, na verdade, o acesso a alimentos por meio da liberalização do comércio mundial e da abertura de oportunidades para as empresas transnacionais, especialmente da indústria química (STÉDILE; CARVALHO, 2013).

Na sua definição, a OMC (WORLD TRADE ORGANIZATION, 2014) afirma que a segurança alimentar diz respeito ao atendimento consistente das necessidades nutricionais de uma dada população ou país. Isso seria efetivado com o "acesso físico e econômico a uma alimentação suficiente, segura e nutritiva". A OMC ainda chama a atenção para o fato de que "segurança alimentar" e "autossuficiência" representam diferentes propostas, destacando que um debate fundamental é saber se as políticas visando a "autossuficiência" ajudam ou atrapalham a segurança alimentar.

As propostas contidas na definição de segurança alimentar projetam, na prática, o aprofundamento da dependência, tanto dos consumidores em relação aos alimentos controlados por sujeitos estranhos ao lugar, do campesinato produtor de alimentos em relação aos baixos preços pagos pelos atravessadores, como também em relação à utilização generalizada de derivados de petróleo. Nesse contexto, o termo "petroalimentos" (VIVAS, 2014) busca traduzir essa condição de dependência em relação aos combustíveis fósseis, resultante da vigência do atual sistema hegemônico de produção e distribuição de alimentos, eufemisticamente apresentado como segurança alimentar.

Na dimensão dos circuitos espaciais ${ }^{2}$ e das distâncias percorridas pelos alimentos, a segurança alimentar explicita suas interfaces de degradação, sobretudo quanto à generalização do consumo de derivados de petróleo e as implicações para o homem

\footnotetext{
${ }^{2}$ Os circuitos espaciais de produção dizem respeito às diferentes etapas pelas quais passam determinados produtos, "desde o começo do processo de produção até chegar ao consumo final" (SANTOS, 1996, p. 49). Neste artigo, denomino como circuitos alimentares a totalidade das etapas pelas quais passam os alimentos (incluídas as etapas pré-plantio) desde campo até o consumidor final.
} 
e o meio ambiente. Referenciado na oferta de alimentos a partir da ativação de extensas redes de transporte, o conceito de segurança alimentar tem no seu cerne a dependência do consumo de derivados de petróleo. De tal modo, por detrás dos alimentos consumidos segundo a proposta da segurança alimentar existe uma agricultura altamente dependente, desde o cultivo, colheita até a comercialização e o consumo. Com promessas de "modernizar a agricultura" e eliminar a fome no mundo, a "revolução verde" tornou-nos dependentes em relação a esse combustível fóssil, o que resultou em uma privatização da agricultura que deixou tanto camponeses como consumidores sob controle das grandes corporações (VIVAS, 2014).

Segundo nos indica a autora, o uso intensivo de adubos e pesticidas químicos representa mais um exemplo de como a atual proposta hegemônica de produção e abastecimento alimentar (a segurança alimentar) é viciada e dependente de petróleo, pois pressupõem quantidades elevadas de fertilizantes fabricados a partir de seus derivados, como amoníaco, ureia, etc., elementos que são utilizados para substituir os nutrientes do solo, esgotados pela exploração intensiva inerente a este modelo predatório de agricultura. Assim, empresas multinacionais petrolíferas como Repsol, Exxon Mobile, Shell e Petrobrás, contam com investimentos na produção e comercialização de uma variedade de fertilizantes agrícolas. Os pesticidas químicos sintéticos representam outra importante fonte da dependência a que estamos submetidos em relação aos combustíveis fósseis, pois impõem quantidades crescentes de petróleo para fabricá-los (VIVAS, 2014).

A dependência em relação ao petróleo pode ser observada, também, pelas longas viagens a que os alimentos são submetidos, desde o local onde são cultivados até o consumidor final. Segundo estimativas descritas por Vivas (2014) para o caso europeu, entre o campo e o prato os alimentos viajam em média 5 mil quilômetros, fato que impõe o consumo de petróleo como parte integrante da produção e do abastecimento alimentar. Mais que alimentos, petroalimentos. A busca pela maximização dos lucros faz com que a produção de alimentos seja "deslocalizada" e concentrada em determinados pontos, independentemente das consequências em termos de redução da qualidade dos produtos, desestruturação do campesinato e poluição ambiental.

Além disso, o modelo supermercadista de abastecimento alimentar implica no consumo generalizado de plásticos derivados de petróleo, pois os alimentos assim adquiridos contém uma variedade de embalagens: uma primeira que envolve o alimento, uma segunda que o rotula e o faz "atraente" para a exibição nas prateleiras e, finalmente, sacolas para o transporte até a residência do consumidor final. Isso resulta em um aumento contínuo da emissão de resíduos sólidos para 
o meio ambiente, poluindo água (inclusive os oceanos), terra e ar. A compra a granel, historicamente praticada, fica cada vez mais na história, pois atualmente os supermercados embalam praticamente tudo (VIVAS, 2014).

Portanto, quanto mais se acentua a "agricultura industrial" e o abastecimento alimentar referenciado na ativação de extensas redes de transporte (segurança alimentar) no bojo do modelo supermercadista, mais intensivo, quilométrico e dependente dos derivados de petróleo. Antagônico ao modelo dominante, os sistemas camponeses, agroecológicos e locais demandam menos recursos e combustíveis. Nesse sentido, é indispensável investir em propostas alternativas, capazes de assegurar os alimentos necessários no presente e no futuro, em consonância com a preservação do meio ambiente e do trabalho no campo, bases fundamentais sobre as quais é possível a construção de sistemas locais e autônomos de abastecimento alimentar, adequados à necessária mudança na forma como produzimos e consumimos a nossa comida (VIVAS, 2014). Mais que segurança (dependência), soberania alimentar, ou seja, autonomia local na tomada de decisões sobre produção e consumo de alimentos, conforme apresento em seguida.

\section{Soberania alimentar: dA PROdUÇÃo AGRíCOLA AO CONTROLE CAMPONÊS} DO MOVIMENTO DOS ALIMENTOS

Diante da dependência subentendida à proposta da segurança alimentar, em meados dos anos 1990 as organizações camponesas reunidas no bojo da Via Campesina contestaram a sua hegemonia, propondo como alternativa o conceito de soberania alimentar ${ }^{3}$. Para tanto, partiram do princípio de que a alimentação não é uma mercadoria, mas sim um direito humano inalienável. A produção e distribuição de alimentos representam uma questão de sobrevivência e, portanto, de soberania pública e nacional. Nesse sentido, soberania alimentar significa que, muito além do simples acesso aos alimentos, a população de cada país tem o direito de produzir e controlar o próprio alimento, pois isso é o que lhes assegura a soberania sobre suas próprias vidas (STÉDILE; CARVALHO, 2013).

Segundo Desmarais (2013, p. 42-43), a soberania alimentar ocupa o centro do modelo alternativo de agricultura proposto pela Via Campesina ${ }^{4}$, no qual

\footnotetext{
${ }^{3}$ Conforme definido originalmente (VIA CAMPESINA, 1996), o conceito de soberania alimentar contempla múltiplas dimensões, desde o acesso à terra e à água, o controle das sementes e dos fluxos alimentares, até o controle da renda gerada pelo trabalho no campo (o controle dos circuitos espaciais dos alimentos em sua totalidade), a utilização de processos agroecológicos, etc., além da questão da qualidade, diversidade e adaptabilidade dos alimentos às mais variadas condições edafoclimáticas e culturais dos povos. Não obstante a abrangência da definição original, dados os limites deste artigo, optei por destacar a importância da identificação dos circuitos espaciais e das distâncias percorridas pelos alimentos.

${ }^{4}$ Composta por organizações e movimentos sociais de diversas partes do mundo, a Via Campesina constitui um movimento internacional de camponeses surgido no ano de 1993 (DESMARAIS, 2013).
} 
figura, na atualidade do comércio globalizado e liberalizado, como "nada menos que revolucionário". De tal modo, a concretização dos objetivos contidos na sua definição requer uma reforma agrária concebida de maneira ampla, que vá além da distribuição de terras, de maneira a envolver "uma reforma abrangente dos sistemas agrícolas para favorecer a produção e a comercialização da pequena agricultura".

A Via Campesina defende uma mudança sobre "quem define e determina o propósito e os termos do conhecimento, da pesquisa, da tecnologia, da ciência, da produção e do comércio relativos aos alimentos" (DESMARAIS, 2013, p. 46). De acordo com a autora, o modelo camponês defendido pela Via Campesina não implica numa aversão à modernidade, à tecnologia ou mesmo ao comércio, mas sim na sua integração cuidadosa com práticas tradicionais. De maneira geral, a Via Campesina declara explícita rejeição ao modelo neoliberal de desenvolvimento do campo e uma recusa total de ser excluída da política de desenvolvimento agrícola (p. 48-49), da qual reivindica o campesinato como protagonista.

Além disso, o controle da produção é fundamental para que os povos tenham acesso garantido a seus próprios alimentos, além de assegurar que os alimentos sejam compatíveis com o meio ambiente em que vivem, com as necessidades nutricionais e com os seus hábitos e culturas alimentares. O conceito de soberania alimentar define que cada comunidade, cada cidade, cada região ou nação tem o direito e o dever de produzir seus próprios alimentos (FÓRUM MUNDIAL PELA SOBERANIA ALIMENTAR, 2007). Não obstante a existência de adversidades naturais, presentes em várias partes do planeta, a humanidade conta com conhecimentos suficientes para garantir a produção (STÉDILE; CARVALHO, 2013, p. 51-52), tanto em termos de quantidade como de qualidade, compatibilidade e variedade.

Interessados em compartilhar os fundamentos da soberania alimentar na construção de políticas alternativas de acesso à terra e combate à fome, diversos Fóruns, Conferências e Reuniões têm se dedicado ao assunto ${ }^{5}$. A Declaração de Nyélény ${ }^{6}$ afirma que a soberania alimentar constitui um direito dos povos a alimentos nutritivos, acessíveis, sintonizados à diversidade cultural e ecológica, além do direito de decidirem sobre seu próprio sistema alimentar e produtivo. Dessa forma, aqueles que produzem, distribuem e consomem alimentos são postos no centro das políticas alimentares, acima das diretrizes dos mercados e das empresas capitalistas. A soberania alimentar nos apresenta, assim, uma importante alternativa ao livre comércio corporativo e ao regime alimentício cada vez mais

\footnotetext{
${ }^{5}$ Cimeira Mundial da Alimentação, Roma/Itália, 1996; Fórum Mundial de Soberania Alimentar, Havana/Cuba, 2001; Conferência Internacional sobre Reforma Agrária e Desenvolvimento Rural, Porto Alegre/Brasil, 2006; Fórum mundial de Soberania Alimentar, Selingue/Mali, 2007, entre outros.

${ }^{6}$ A Declaração de Nyélény refere-se aos principais assuntos debatidos e deliberados por 600 delegados de 80 países no âmbito do Fórum mundial de soberania alimentar, realizado no Mali no ano de 2007.
} 
industrializado, canalizando "os sistemas alimentares, agrícolas, pastoris e de pesca para a prioridade das economias locais e os mercados locais e nacionais" (FÓRUM MUNDIAL PELA SOBERANIA ALIMENTAR, 2007).

$\mathrm{Na}$ esteira das ações promovidas pelos movimentos sociais, sobretudo àqueles vinculados à Via Campesina, os debates em torno do conceito de soberania alimentar buscam alternativas para o desenvolvimento da produção local de alimentos. Mais que isso, os debates em torno da soberania alimentar buscam "garantir a produção de alimentos na linha direta da decisão dos povos, da classe trabalhadora sobre o que, como, quanto e em quais condições se produzir" (THOMAZ JUNIOR, 2008, p. 08). Nesse sentido:

A Soberania Alimentar supõe novas relações sociais, libertas das determinações do capital, portanto da opressão e das desigualdades entre homens e mulheres, grupos raciais, classes sociais, sendo que o direito de acesso à terra, à água, aos recursos públicos para produzir, às sementes e à biodiversidade seja garantido para aqueles que nela produzem os alimentos, social e culturalmente definidos pelos trabalhadores, ou seja, produtores e consumidores (THOMAZ JUNIOR, 2008, p. 25).

O documento preparado pelo Comitê Internacional de Planejamento para a soberania alimentar (IPC) a pedido da Organização das Nações Unidas para a Agricultura e alimentação (FAO), considera a soberania alimentar como um conjunto de políticas e ações necessárias para que a reforma agrária e o desenvolvimento rural possam verdadeiramente reduzir a pobreza e cumprir o direito à alimentação, à terra, à elaboração de políticas próprias de agricultura e alimentação em respeito aos territórios indígenas, pescadores tradicionais, etc. e o estabelecimento de prioridade para a produção alimentar voltada aos mercados locais (CONFERÊNCIA INTERNACIONAL SOBRE REFORMA AGRÁRIA E DESENVOLVIMENTO RURAL, 2006).

Em uma definição ampla, a Via Campesina (1996) considera a soberania alimentar como o direito de todos os povos e/ou países poderem decidir sobre suas próprias políticas de agricultura e alimentação, de forma a privilegiar a produção local para o abastecimento das áreas próximas e, assim, assegurar o direito de cada nação manter e desenvolver a sua própria capacidade de produzir seus alimentos básicos, respeitando a diversidade cultural, ambiental e produtiva).

Para que a soberania alimentar traduza os anseios preconizados na sua definição original, faz-se necessário considerar a complexidade da questão alimentar, o que impõe defini-la para além de um simples direito de acesso à alimentação, 
na dimensão do direito ao controle dos circuitos alimentares, de maneira que os alimentos sejam produzidos e consumidos numa perspectiva de soberania local/ regional (circuitos espaciais os mais curtos possíveis), sem a participação de intermediários entre o produtor e o consumidor ${ }^{7}$. O conceito de soberania alimentar expõe esta perspectiva de maneira a considerar as distâncias percorridas pelos alimentos, assim como os sujeitos e territórios existentes entre os extremos da alimentação, desde a semente lançada na terra até a disponibilização do alimento para as pessoas ${ }^{8}$.

Portanto, se a produção e distribuição dos próprios alimentos é parte fundamental da soberania dos povos, esta não pode ser negociada ou depender da vontade política de governos de outros países. Menos ainda estar subordinada aos mercados. Conforme já nos advertiu José Martí, um povo que não pode produzir seus próprios alimentos é um povo escravizado. Escravizado e dependente de outra nação que lhe propõe as condições para sobreviver. A soberania alimentar contrapõese a hegemonia do neoliberalismo, situando aqueles que produzem, distribuem e consomem alimentos no centro das políticas alimentares, acima das exigências dos mercados e das corporações transnacionais. Assim definida, a soberania alimentar é mais que um conceito. É um princípio ético e um estilo de vida que não se limita a uma definição acadêmica, pois surge de um processo coletivo e participativo, popular e progressista (STÉDILE; CARVALHO, 2013, p. 52-53).

Logo, a soberania alimentar estabelece:

[...] el derecho de los pueblos a definir sus propias políticas agrícolas y alimentarias, que incluyen protección del ambiente, regulación de la producción de la pesca y el comercio interno agrícola para el desarrollo sustentable, protección de los productores locales y los mercados nacionales contra las importaciones y los límites en el mercado y la pérdida de valor de los productos sociales y económicos. Esto respalda el derecho a decidir cómo organizar qué se produce y ordenar la distribución y consumo de alimentos en relación con las necesidades de las comunidades, en cantidades suficientes y calidad óptima, dando prioridad a los productos y variedades locales (STÉDILE; CARVALHO, 2013, p. 54).

A soberania alimentar define, assim, uma alternativa às políticas neoliberais, de modo que os cidadãos possam determinar suas próprias políticas alimentares

\footnotetext{
${ }^{7}$ A soberania está, nesse sentido, no domínio integral da territorialidade produção-distribuição pelo campesinato, o que favorece, por um lado, alimentos de baixa quilometragem, maior qualidade e menores preços e, por outro, a incorporação da maior parte da renda gerada e o fortalecimento da família camponesa e da renda local e regional.

${ }^{8}$ Conforme definida pela Via Campesina (1996), a soberania alimentar se inicia antes da semente ser lançada na terra, com a utilização de processos agroecológicos e a produção interna da maior parte dos insumos utilizados.
} 
e agrícolas e, com isso, decidirem o que, como, onde e quem produz. É o direito de terem acesso à água, à terra e às sementes. Para tanto, demandam políticas baseadas na solidariedade entre produtores e consumidores, posto que é impossível manter políticas soberanas com base no livre mercado. A proposta da soberania alimentar assegura a oferta de alimentos socialmente sustentáveis e ecologicamente produtivos, que geram trabalho para as pessoas em todos os lugares (NICHOLSON, 2013, p. 41).

Nesse sentido, a produção com base em processos agroecológicos compõe uma das dimensões que compõem soberania alimentar, sendo indissociável desta, pois a sua utilização implica na independência (mesmo que relativa) do produtor em relação à indústria. Assim, a soberania alimentar restrita apenas à dimensão do controle dos fluxos alimentares (circuitos espaciais percorridos pelos alimentos) funciona como um tipo de "soberania relativa", pois ainda subordinada ao capital via utilização de insumos derivados do paradigma de industrialização da agricultura (quimicalização, tecnificação, engenharia genética, etc.).

Apesar de muito ambicioso e de difícil implantação em sua integralidade, acredito que o desafio da soberania alimentar deve ser encarado como referência a ser seguida, pois quanto mais próximos estivermos da sua concretização (mesmo que inicialmente restrita à dimensão do controle dos fluxos alimentares), menores serão as distâncias percorridas, os preços e a deterioração dos alimentos. Se hoje a soberania alimentar constitui um grande desafio, amanhã pode compor a base para uma nova relação entre alimento e alimentação, produtor e consumidor, numa utopia realista que considere a importância de encarar o alimento na dimensão da comida e não apenas da mercadoria.

\section{PARA ALÉM DO CONFRONTO TEÓRICO E CONCEITUAL: PROJETOS DE SOCIEDADE}

\section{EM DISPUTA}

Das definições apresentadas até agora acerca da segurança e da soberania alimentar, sobressaem distintos projetos de sociedade ou, mais especificamente, diferentes propostas de produção e abastecimento alimentar. Considerado a partir dos circuitos espaciais e das distâncias percorridas, o movimento dos alimentos demarca os sentidos e interesses por detrás de cada concepção. Se a soberania emana produção local para abastecimento local e regional, a segurança projeta o abastecimento referenciado na ativação de extensas redes de transporte. É óbvio que, no âmbito do atendimento regular das necessidades alimentares demandadas pela população de determinado território, existe uma relação direta entre soberania alimentar e segurança alimentar. Não obstante, é importante destacar que, 
considerada a partir das referências da soberania alimentar, a segurança alimentar é sempre o produto e não o processo. Isto é, a segurança (garantia de acesso suficiente e regular) surge a partir da soberania (controle camponês da produção e distribuição local/regional).

Contudo, no plano institucional essa lógica é claramente pervertida. De acordo com a Lei $\mathrm{n}^{\circ} 11.346$, de 15 de setembro de 2006, que institui o Sistema Nacional de Segurança Alimentar (SISAN), a soberania alimentar e o direito humano à alimentação compõem os dois princípios orientadores de ações intersetoriais relacionadas à segurança alimentar e nutricional. Nessa concepção, a soberania está contida e subordinada à segurança, em uma definição que restringe a soberania ao potencial produtivo na escala do território nacional.

Por conseguinte, a única associação razoável do ponto de vista da precisão conceitual que pressupõe o debate entre segurança e soberania alimentar (principalmente quando consideramos o contexto histórico e político em que surgem os diferentes conceitos), consiste em inverter a hierarquia apresentada no plano institucional. Ou seja, ao contrário do entendimento de que a soberania alimentar está contida na segurança alimentar (como apresentado pela Lei $n^{\circ}$ 11.346, de 15 de setembro de 2006), penso que é a segurança que se subordina à soberania. Isso porque a soberania alimentar (produção local para abastecimento local e regional) contempla a segurança alimentar (garantia de acesso regular aos alimentos), enquanto o oposto não é verdadeiro.

A abordagem legal sobre soberania alimentar anula os sentidos teóricos e, principalmente, políticos inerentes à concepção original (VIA CAMPESINA, 1996). De um movimento organizado a partir "de baixo" através de associações camponesas reunidas no arco da Via Campesina para contestar o modelo hegemônico de produção e abastecimento, com o objetivo de buscar formas de desenvolvimento lastreadas na produção e distribuição local/regional de alimentos com base em processos agroecológicos, a soberania alimentar é descrita meramente como um "princípio" (junto com o direito humano à alimentação) que orientaria a Lei de Segurança Alimentar e Nutricional.

Nessa concepção de "colocar as coisas no seu devido lugar", em uma abordagem que relaciona a agroecologia à construção da soberania alimentar por meio da agricultura camponesa, Altieri (2010, p. 23) argumenta que os "sistemas de produção baseados na agroecologia" e na soberania alimentar "podem melhorar a segurança alimentar", pois contribuem na conservação dos recursos naturais, da agrobiodiversidade, dos solos e da água. A segurança alimentar representa,

\footnotetext{
9“Aplicação de conceitos e princípios ecológicos ao desenho e manejo de agroecossistemas sustentáveis” (ALTIERI, 2010, p. 23).
} 
nesse contexto, a garantia de acesso regular aos alimentos demandados pela população de determinados territórios, a partir dos próprios territórios e com base em processos agroecológicos. Nesse sentido, a diferença em relação à definição oficial de segurança alimentar (Lei n ${ }^{\circ} 11.346$, de 15 de setembro de 2006) está no questionamento enfático em relação à onde, como e por quem os alimentos são produzidos.

O fulcro da questão está no fato de que a produção e distribuição de alimentos referenciados na generalização do movimento dos alimentos no espaço (a garantia de acesso suficiente e regular ou a segurança alimentar) pode existir sem que haja a soberania, como prova a vigência do atual sistema hegemônico de produção e abastecimento alimentar (ESTEVE, 2017; MCMICHAEL, 2016; PLOEG, 2008). Já a produção local para abastecimento local/regional com base em processos agroecológicos (a soberania alimentar), quando adotada, nunca está sozinha, posto que implica necessariamente no fortalecimento da segurança alimentar, ou seja, na garantia de acesso suficiente e regular aos alimentos necessários para uma determinada população.

De tal modo, o embate entre os conceitos de segurança e soberania alimentar ocorre no âmbito da negação do segundo por parte do primeiro, incumbido da tarefa de "naturalizar" o abastecimento via generalização do movimento dos alimentos no espaço. Com isso, "há um confronto entre modos de fazer agricultura" (e de diferentes formas de distribuição de alimentos), sobretudo em relação àqueles que sejam capazes de projetar um futuro promissor a partir da necessidade de produzir alimentos para toda a humanidade de maneira efetivamente sustentável. Não obstante, devido à sua prioridade estar assentada na maximização dos lucros e não no atendimento das necessidades alimentares das pessoas, essa não pode ser a agenda do capital, a não ser "como farsa ou cinismo". Em tempos de crise o capital pode até admitir o debate da "segurança" alimentar, "mas não pode, sem trair a si mesmo, aceitar o debate acerca da 'soberania alimentar" (CALDART, et al., 2012, p. 15).

\section{CONSIDERAÇÕES FINAIS}

A precisão teórica e conceitual pressupõe uma postura clara em relação aos contornos específicos que definem diferentes propostas de produção e distribuição de alimentos. Nesse sentido, conforme detalhei anteriormente, soberania alimentar e segurança alimentar só podem estar juntas no âmbito da vigência da primeira, posto que assim fica assegurado o acesso suficiente e regular aos alimentos (segurança alimentar). Da maneira que está formatado o atual sistema hegemônico 
de produção e distribuição, fundado na generalização do movimento dos alimentos no espaço, segurança alimentar e soberania alimentar são, a rigor das suas definições, reciprocamente excludentes. Isso porque, enquanto diferentes propostas de produção e abastecimento alimentar, ao passo que a segurança alimentar busca garantir a reprodução do sistema hegemônico, ou seja, o abastecimento alimentar referenciado na ativação de extensas redes de transporte, sobretudo rodoviário, a soberania alimentar tem por prioridade a superação de tais relações, principalmente no que diz respeito à dependência e à fragilidade dos atuais mecanismos de produção e distribuição.

A fragilidade do atual sistema de produção e abastecimento alimentar foi exposta de maneira incisiva na recente greve dos caminhoneiros, iniciada no dia 21 de maio de 2018 em praticamente todos os estados do Brasil. Motivada principalmente pela constante alta nos preços do diesel, decorrente da implantação da recente política de preços dos combustíveis praticada pela Petrobrás, que levou a reajustes diários, supostamente atrelados à variação internacional do petróleo, essa greve explicitou os contornos da dependência a que estamos sujeitos em relação ao abastecimento referenciado na ativação de redes de transporte em grandes distâncias, quase que exclusivamente baseadas no modal rodoviário. No que concerne ao abastecimento alimentar e, mais especificamente em relação às frutas, legumes e verduras, os efeitos foram sentidos rapidamente e em todo o território nacional, principalmente nas grandes centrais de distribuição (CEASA, CEAGESP, etc.).

Pelo fato do sistema hegemônico de abastecimento alimentar estar assentado na centralização dos produtos via grandes entrepostos de alimentos, as implicações da paralização dos caminhoneiros extrapolaram as centrais e em passo acelerado chegaram aos consumidores, como apontam Tomazela; Batista; Jansen e Souza (2018) em relação ao comprometimento do abastecimento de diversos supermercados em São Paulo e no Rio de Janeiro. Com isso, vários itens começaram a faltar nas prateleiras, ocasionando uma alta abrupta nos preços. O preço do saco de batatas $(60 \mathrm{~kg})$, por exemplo, que antes da greve era vendido por $\mathrm{R} \$ 60,00$, passou a ser negociado por até $\mathrm{R} \$ 300,00$. A unidade da CEAGESP de Presidente Prudente/SP chegou a funcionar com horário reduzido devido à falta de diversos produtos. De acordo com um dos permissionários entrevistados neste dia, “o que está salvando é o que vem daqui", referindo-se aos alimentos produzidos no município e região, que tem mantido o abastecimento de algumas frutas, legumes e verduras.

Como o acesso aos alimentos é intermediado pelo poder de compra, a alta dos preços implica diretamente na redução do acesso das famílias aos alimentos, sobretudo para as mais carentes. Independentemente da ocorrência de uma 
situação extrema, como a paralização dos caminhoneiros (cujas implicações para o abastecimento foram agravadas pela absoluta dependência em relação à generalização do movimento dos alimentos no espaço), os custos decorrentes do transporte e armazenamento recaem, invariavelmente, nos preços pagos pelos consumidores finais. Portanto, a defesa da soberania alimentar é a defesa de uma alimentação emancipada do jugo do capital, de maneira que o movimento dos alimentos traduza o controle dos fluxos nas escalas local e regional (circuitos curtos), no âmbito do estabelecimento de relações diretas entre produtores e consumidores e, por conseguinte, de fortalecimento do sistema de produção e abastecimento alimentar, assim como da democratização do acesso das pessoas aos alimentos.

\section{REFERÊNCIAS}

ALTIERI, M. Agroecologia, agricultura camponesa e soberania alimentar. Revista Nera, Presidente Prudente/SP, ano 13, nº 16, p. 22-32, 2010. Disponível em: $<\underline{\text { http://revista.fct.unesp.br/index.php/nera/article/view/1362/1347> }}$. Acesso em: $12 / 02 / 2018$.

BRASIL. Lei n ${ }^{\circ} 11.346$, de 15 de setembro de 2006. Dispõe sobre a criação da Lei de segurança alimentar e nutricional. Lei de segurança alimentar e nutricional: conceitos, Brasília, 2006. Disponível em: $<$ http://www.planalto.gov. br/consea/3conferencia/static/Documentos/Cartilha_CONSEA-2007_NOVO.pdf $>$. Acesso em: 03/05/2014.

CALDART, et al. Dicionário da educação do campo. São Paulo: Expressão Popular, 2012.

CONFERÊNCIA INTERNACIONAL SOBRE REFORMA AGRÁRIA E DESENVOLVIMENTO RURAL. A Reforma Agrária no contexto da Soberania Alimentar, o direito à alimentação e diversidade cultural: "Terra, Território e Dignidade". Porto Alegre, 2006. Disponível em: < http://www.icarrd.org/po/ icard_doc_down/Issue_Paper5.pdf $>$. Acesso em: 12/08/2009.

CONSEA/FAO/IICA. Construção do Sistema e da Política nacional de Segurança Alimentar e Nutricional: a experiência brasileira. Brasília: 2009. Disponível em: $<$ https://www.fao.org.br/download/Seguranca_Alimentar_Portugues.pdf $>$. Acesso em: 01/05/2014. 
CUSTÓDIO, M. B. et al. Segurança alimentar e nutricional e a construção de sua política: uma visão histórica. Campinas: Segurança Alimentar e Nutricional, 2011. Disponível em: $<$ http://www.unicamp.br/nepa/arquivo_san/volume 13 6_2011/1Seguranca-alimentar_13-06-2011.pdf $>$. Acesso em: 18/03/2014.

DESMARAIS, A. A. A Via Campesina. São Paulo: Cultura Acadêmica; Expressão Popular, 2013.

FÓRUM MUNDIAL PELA SOBERANIA ALIMENTAR, 2007, Selingue/

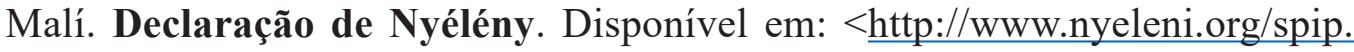
php?article327>. Acesso em: 24/05/2013.

JAPIASSU, H. O mito da neutralidade científica. Rio de Janeiro: Imago, 1975.

MACEDO et al. A construção da política de segurança alimentar e nutricional no Brasil. Simbio-Logias, v. 02, n. 01, 2009. Disponível em: $<\underline{\text { http://www.ibb.unesp. }}$ br/Home/Departamentos/Educacao/Simbio-Logias/A_Construcao_da_Politica de Seguranca.pdf>. Acesso em: 30/05/2014.

MALUF, R. S.; MENEZES, F.; VALENTE, F. L. Contribuição ao tema da segurança alimentar no Brasil. Cadernos de Debate, Campinas, vol. IV, p. 66-88, 1996.

MENEZES, F. O conceito de segurança alimentar. São Paulo, Actionaid, 1998. Não paginado. Disponível em: $<\underline{\text { http://amar-bresil.pagesperso-orange.fr/documents/ }}$ secual/san.html>. Acesso em: 18/03/2014.

NICHOLSON, P. Soberanía alimentaria: alianzas y transformación. In: ILSA (Instituto Latinoamericano para una Sociedad y un Derecho Alternativos); FOOD FIRST (Institute for Food and Development Policy). ¡Movimientos alimentarios uníos! Estrategias para transformar nuestros sistemas alimentarios, Bogotá: Colección en clave de sur, 2013.

SANTOS, M. Metamorfoses do espaço habitado. São Paulo: Hucitec, 1996.

STÉDILE, J. P.; CARVALHO, H. M. de. Soberanía alimentaria: una necesidad de los pueblos. In: ILSA (Instituto Latinoamericano para una Sociedad y un Derecho Alternativos); FOOD FIRST (Institute for Food and Development Policy). 
¡Movimientos alimentarios uníos! Estrategias para transformar nuestros sistemas alimentarios, Bogotá: Colección en clave de sur, 2013.

THOMAZ JUNIOR, A. Totalidade Viva do Trabalho, Reforma Agrária e Soberania Alimentar. (Uma Reflexão Autocrítica da Classe Trabalhadora e a Luta de Classes no Brasil). In: BATISTA, R. L.; TUMOLO, P. Trabalho, Economia e Educação. Londrina: Práxis, 2008.

TOMAZELA, J. M.; BATISTA, R.; JANSEN, R.; SOUZA, D. Greve de caminhoneiros provoca falta de alimentos e combustível em SP e no Rio. (2018) Disponível em: <https://economia.estadao.com.br/noticias/geral,grevede-caminhoneiros-provoca-falta-de-alimentos-e-combustivel-em-sp-e-norio,70002320482>. Acesso em: 24/05/2018.

VALÉRIO, V. J. de O. A segurança da dependência e os desafios da soberania: expansão da agroindústria canavieira e a geografia do abastecimento alimentar no município de Tupi Paulista/SP. 2015. 230 f. Dissertação (Mestrado em Geografia) Faculdade de Ciências e Tecnologia de Presidente Prudente, Universidade Estadual Paulista (FCT/UNESP), Presidente Prudente/SP.

VIA CAMPESINA. The right to produce and access to land. Rome: Via Campesina, 1996. Disponível em: <http://www.voiceoftheturtle.org/ library $/ 1996 \% 20$ Declaration $\% 20$ of $\% 20$ Food $\% 20$ Sovereignty.pdf $>$. Acesso em: 25/11/2011.

VIVAS, E. Uma alimentação viciada em petróleo. Barcelona, 2014. Disponível em: <http://esthervivas.com/portugues/uma-alimentacao-viciada-em-petroleo/>. Acesso em: 07/08/2014. (não paginado).

WORLD TRADE ORGANIZATION (WTO). Food security: definition glossary. [2014]. Disponível em: $<$ http://www.wto.org/english/thewto_e/glossary_e/food security e.htm $>$. Acesso em: 07/02/2015. 